\title{
Relationship between landform and soil salinity in the surface and subsurface soils (case study: Southeast of Fars Province, Iran)
}

\author{
Marzieh Mokarram ${ }^{1} \cdot$ Mahdi Najafi-Ghiri ${ }^{1} \cdot$ Saeed Negahban $^{2} \cdot$ Gholamreza Roshan $^{3}$
}

Received: 25 December 2015/Accepted: 30 December 2015/Published online: 22 January 2016

(C) Springer International Publishing Switzerland 2016

\begin{abstract}
Forty surface and subsurface soil samples were collected from agricultural field of Darab, southern Iran. Some physicochemical properties and also EC were determined. Geostatistical analysis was done by using the Kriging method (including ordinary, simple, universal, indicator, probability and disjunctive models) in ArcGIS 10.2 software. The results of stepwise multiple regressions indicate that in the surface and subsurface soils, sand and silt contents respectively are the most influential soil characteristics that predict EC. The root mean square error (RMSE) analysis of the different models indicated that indicator model with RMSE value of 0.518 and probability model with RMSE 0.509 are the best models for the description of the spatial distribution of EC in the surface and subsurface soils, respectively. Finally, for determination of accuracy of the best models (indicator and probability models) in surface and subsurface soils, 10 sample points were used. The RMSE values for EC in the surface and subsurface soils were calculated 0.476 and 0.349 , respectively. It is recommended that other interpolation
\end{abstract}

Gholamreza Roshan

r.rowshan@yahoo.com; ghr.roshan@gu.ac.ir

Marzieh Mokarram

m.mokarram@shirazu.ac.ir

Mahdi Najafi-Ghiri

mnajafighiri@yahoo.com

Saeed Negahban

snegahban@shirazu.ac.ir

1 Department of Range and Watershed Management, College of Agriculture and Natural Resources, Shiraz University, Shiraz, Iran

2 Department of Geography, Shiraz University, Shiraz, Iran

3 Department of Geography, Golestan University, Gorgan, Iran methods such as co-Kriging and soil properties such as CEC and SAR are used in order to prepare precision maps in the future. Finally the relationship between landform classes and EC values were determined by using topography position index. The results show that the high EC value was shown in plain small for subsurface soil and surface soil in the study area. While the low EC value was seen in mountain top and stream for subsurface soil and surface soil that was indicative leaching of the soil.

Keywords Electrical conductivity - Spatial distribution Kriging · Topography position index (TPI) - Landform class $\cdot$ Soil salinity

\section{Introduction}

Soil salinity is an important factor for land suitability evaluation for agricultural purpose. Soil electrical conductivity (EC) as an index of soil salinity affects plant growth and development, plant nutrient availability, and activity of soil microorganisms. According to the U.S. Salinity Laboratory Staff (1954), a saline soil has an electrical conductivity of the saturation extract (EC) of more than $4 \mathrm{mmhos} / \mathrm{cm}$. Soils containing excess salts occur naturally in arid and semiarid climates. Salt may accumulate in soils as a result of soil parent material, the atmosphere, runoff water, groundwater, and plant residues (Roshan and Negahban 2015). Although EC does not provide a direct measurement of specific ions or salt compounds, it has been correlated to concentrations of nitrates, potassium, sodium, chloride, sulfate, and ammonia (Kazemi 2012).

In recent years, geostatistics has been proven to effectively assess the variability of soil properties (Webster 
1994; Zhang et al. 1998, 2000; Webster and Oliver 2001; Corwin and Lesch 2003; Mueller et al. 2003; Sun et al. 2009; Kazemi 2012; Sun et al. 2012; Li et al. 2015). Geostatistical analysis obtains a set of statistical tools for analyzing spatial variability and spatial interpolation in ArcGIS software. A semivariogram is used to describe the structure of spatial variability. The semivariogram has an important role in the analysis of geostatistical data using the Kriging method (Kazemi 2012). Autocorrelation in data to create mathematical models of spatial correlation structures commonly expressed was taken by variograms in the Kriging method (Gundogdu and Guney 2007; Kazemi 2012).

Mashayekhi et al. (2007) investigated regional variation of salinity in southern Lenjan-Isfahan (Iran) with geostatistical methods. Soil samples were obtained from 0 to $0.2,0.2$ to 0.5 and 0.5 to $1.0 \mathrm{~m}$ depths. EC and SAR maps in all depths were prepared by Kriging and cokriging. Pisinaras et al. (2010) used spatial distribution maps for $\mathrm{pH}$ and $\mathrm{EC}$ of soil extracts using Ordinary kriging interpolation in the agricultural lands of Rhodope District, northeastern Greece. Kazemi 2012 used the spatial distribution of EC and $\mathrm{pH}$ on agricultural fields of Golestan province. They used some interpolation methods such as kriging with different models, inverse distance weighted (IDW) and radial basis function (RBF) for preparation of spatial distribution maps. The results show that exponential model-based kriging had the highest precision for estimation of soil EC in this area. Also, radial basis function (TPS) model was the most unsuitable method for estimation of these soil properties. Also semivariograms analysis indicated that $\mathrm{pH}$ and $\mathrm{EC}$ were best fitted to Spherical model.

$\mathrm{Li}$ and et al. 2015 used REML and universal kriging for preparing of soil salinity map in the Yangtze delta. They compared the results by cross-validation and calculated the mean errors (MEs), mean squared errors (MSEs) and mean squared deviation ratios (MSDRs). The combination with an MSDR closest to 1 was UK with the spherical variogram estimated by REML; its MSDR was 0.993 .

The main purposes of this study were to obtain a relationship between soil salinity and some physicochemical properties of surface $(0-20 \mathrm{~cm})$ and subsurface soils (20-40 cm) and to provide a spatial distribution map for soil electrical conductivity (EC) in Darab region located southeast of Fars province, Iran and also to develop the best model for creation of spatial distribution map by kriging method. Since there is relationship between EC and landform classes (Akpabio and Agbasi 2011), their relationship was determined in the study area.

\section{Materials and methods}

\section{Case study}

The study area is located in southeast of Fars province, Iran, between latitudes $28^{\circ} 42^{\prime} 10^{\prime \prime} \mathrm{N}-29^{\circ} 00^{\prime} 00^{\prime \prime} \mathrm{N}$ and longitudes $54^{\circ} 25^{\prime} 58^{\prime \prime} \mathrm{E}-48^{\circ} 47^{\prime} 16^{\prime \prime} \mathrm{E}$ with an area of $1026.56 \mathrm{~km}^{2}$ (Fig. 1).

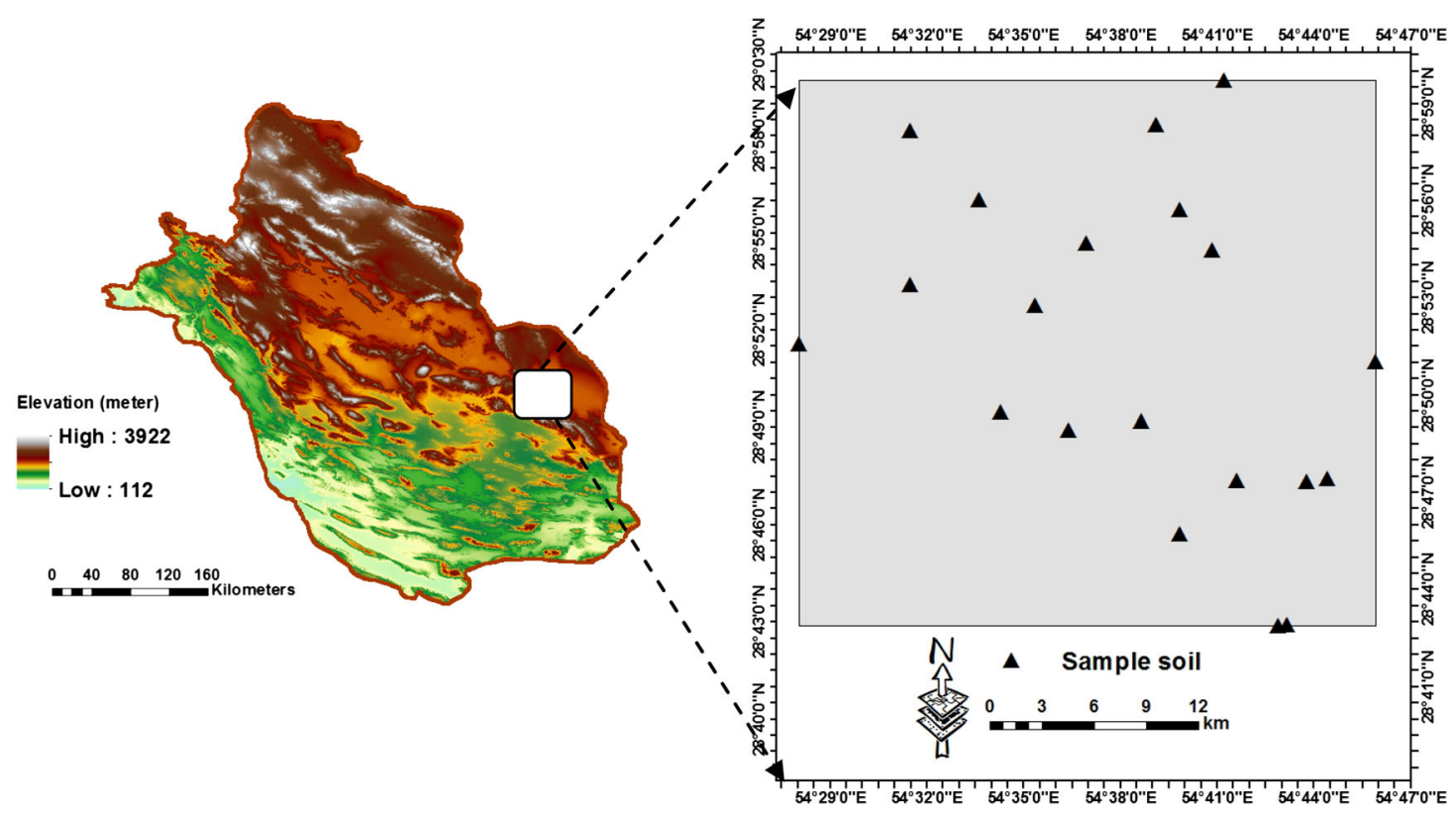

Fig. 1 Location of the study area 


\section{Soil sampling and physicochemical analysis}

Forty surface $(0-20 \mathrm{~cm})$ and subsurface $(20-40 \mathrm{~cm})$ soil samples were collected randomly from the study area by auger. Samples were air-dried and sieved $(<2 \mathrm{~mm})$ for laboratory analyses. Particle size distribution analysis was carried out according to method of Rowell (1994), calcium carbonate equivalent (CCE) by acid neutralization (Salinity Laboratory Staff 1954), electrical conductivity (EC) in saturation extract, soil $\mathrm{pH}$ in saturated soil paste (Salinity Laboratory Staff 1954) and cation exchange capacity (CEC) with sodium acetate at $\mathrm{pH} 8.2$ (Chapman 1965).

Statistical analysis was performed by the software SPSS for Windows v. 15 (two-tailed for test of correlation significance).

\section{Statistical analysis}

Using measured sample point EC from the study area, geostatistical analyst was used to provide accurate predictions for other unmeasured locating within the case study.

Geostatistical analysis of data occurs in two phases:

1. Modeling the semivariogram to analyze surface properties

\section{Kriging}

The semivariogram was used in this study to analyze soil EC values. Semivariogram is computed as half the average squared difference between the components of data pairs (Goovaerts 1999, Kazemi 2012). The function is expressed as:

$\gamma(h)=\frac{1}{2 N(h)} \sum_{i=1}^{N(h)}\left[Z\left(x_{i}\right)-Z\left(x_{i}+h\right)\right]^{2}$

where $N(h)$ is the total number of data pairs separated by a distance; $h ; Z$ represents the measured value for soil property; and $\mathrm{x}$ is the position of soil samples.

A semivariogram is calculated for classes of distance between sample pairs before the geostatistical estimation. Several standard models are available to fit the experimental semivariogram, e.g., spherical, exponential, Gaussian, linear and power models (Shi et al. 2007). In this study, the exponential models were selected for Ordinary, simple, universal, indicator, probability and disjunctive.

Kriging is an important tool in geostatistics. Kriging is a linear interpolation procedure that provides a best linear unbiased estimation for quantities which vary in space (Cressie 1990). Kriging is a theoretical weighted moving average (Krige 1951):

$\hat{Z}\left(x_{o}\right)=\sum_{i=1}^{n} \lambda_{i} Z\left(x_{i}\right)$ where $\hat{Z}\left(x_{o}\right)$ is the value to be estimated at the location of $x_{0}, z\left(x_{i}\right)$ is the known value at the sampling site $x_{i}$ and $n$ is the number of sites within the search neighborhood used for the estimation (Robinson and Metternicht 2006).

\section{Comparison of different models}

In the study, root mean square error (RMSE) were used for evaluation of interpolation methods:

$R M S E=\sqrt{\frac{1}{N} \sum_{k=1}^{N}\left[Z\left(x_{i}\right)-Z^{*}\left(x_{i}\right)\right]^{2}}$

where: $\mathrm{Z}(\mathrm{xi})$ is observed value at point $\mathrm{xi}, \mathrm{Z}^{*}(\mathrm{xi})$ is predicted value at point $\mathrm{xi}, \mathrm{N}$ is the number of samples.

\section{Landform classification using topographic position index (TPI)}

TPI (Weiss, 2001) compares the elevation of each cell in a DEM to the mean elevation of a specified neighborhood around that cell. Positive TPI values represent locations that are higher than the average of their surroundings, as defined by the neighborhood (ridges). On the other hand, negative TPI values represent locations that are lower than their surroundings (valleys). TPI values near zero are either flat areas (where the slope is near zero) or areas of constant slope (where the slope of the point is significantly greater than zero) (Weiss 2001).

TPI (Eq. (4)) compares the elevation of each cell in a DEM to the mean elevation of a specified neighborhood around that cell. Mean elevation is subtracted from the elevation value at the center (Weiss 2001):

$T P I_{i}=Z_{0}-\sum_{n-1} Z_{n} / n$

where $Z_{0}=$ elevation of the model point under evaluation, $Z_{n}=$ elevation of grid

$\mathrm{n}=$ the total number of surrounding points employed in the evaluation.

Combining TPI at small and large scales allows a variety of nested landforms to be distinguished Table 1 . The exact breakpoints among classes can be manually chosen to optimize the classification for a particular landscape. As in slope position classifications, additional topographic metrics, such as variances of elevation, slope, or aspect within the neighborhoods, may help delineate landforms more accurately (Weiss 2001).

The classes of canyons, deeply incised streams, midslope and upland drainages, and shallow valleys tend to have strongly negative plane form curvature values. On the other hand, local ridges/hills in valleys, midslope ridges, 
Table 1 Landform classification based on TPI (Source: Weiss 2001)

\begin{tabular}{ll}
\hline Classes & Description \\
\hline Canyons, deeply incised streams & Small neighborhood: zo $\leq-1$ \\
Midslope drainages, shallow valleys & Large neighborhood: zo $\leq-1$ \\
& Small neighborhood: zo $\leq-1$ \\
upland drainages, headwaters & Large neighborhood: $-1<$ zo $<1$ \\
U-shaped valleys & Small neighborhood: zo $\leq-1$ \\
& Large neighborhood: zo $\geq 1$ \\
Plains small & Small neighborhood: $-1<$ zo $<1$ \\
& Large neighborhood: zo $\leq-1$ \\
Open slopes & Neighborhood: $-1<$ zo $<1$ \\
& Large neighborhood: $-1<$ zo $<1$ \\
Upper slopes, mesas & Slope $\leq 5^{\circ}$ \\
Local ridges/hills in valleys & Small neighborhood: $-1<$ zo $<1$ \\
Midslope ridges, small hills in plains & Large neighborhood: $-1<$ zo $<1$ \\
Mountain tops, high ridges & Slope $>5^{\circ}$ \\
& Small neighborhood: $-1<$ zo $<1$ \\
& Large neighborhood: zo $\geq 1$ \\
& Small neighborhood: zo $\geq 1$ \\
& Large neighborhood: zo $\leq-1$ \\
& Small neighborhood: zo $\geq 1$ \\
& Large neighborhood: $-1<$ zo $<1$ \\
& Small neighborhood: zo $\geq 1$ \\
& Large neighborhood: zo $\geq 1$ \\
\hline
\end{tabular}

small hills in plains and mountain tops, and high ridges have strongly positive plane form curvature values.

\section{Results and discussion}

Table 2 indicated some physicochemical properties of the studied soils. All soils are calcareous with CCE of 36-62 and 38-57 \% for surface and subsurface soils, respectively. Soil reaction are alkaline. Soil electrical conductivity ranged from 0.3 to $5.5 \mathrm{dS} \mathrm{m}^{-1}$ and according to the US Salinity Laboratory Staff (1954) nearly $10 \%$ of the studied soils are saline $\left(\mathrm{EC}>4 \mathrm{dS} \mathrm{m}^{-1}\right)$. There was no significant difference between surface and subsurface soils in all soil properties. Cation exchange capacity ranged from 7 to 21 and 6 to $19 \mathrm{cmol}+\mathrm{kg}^{-1}$ for surface and subsurface soils, respectively. There was a positive and significant relationship $\left(\mathrm{r}=0.82^{* *}\right)$ between clay and EC.

The results of stepwise multiple regressions indicate that in the surface soils, sand content have most influence, whereas in the subsurface soils, silt content are the most influential soil characteristics that predict EC as follows:

EC of surface soil $=1.96-0.032$ (sand content) $\left(\mathrm{R}=0.463^{*}\right)$.

EC of subsurface soil $=-1.654+0.085$ (silt content) $\left(\mathrm{R}=0.464^{*}\right)$.
Table 2 Some

physicochemical properties of surface and subsurface soils of the studied region

\begin{tabular}{|c|c|c|c|c|c|c|}
\hline \multirow[t]{2}{*}{ Soil properties } & \multicolumn{3}{|c|}{ Surface soil $(0-20 \mathrm{~cm})$} & \multicolumn{3}{|c|}{ Subsurface soil $(20-40 \mathrm{~cm})$} \\
\hline & Range & Mean & SE & Range & Mean & SE \\
\hline Clay, \% & $15-52$ & $33 \mathrm{a}$ & 11 & $15-56$ & $34 \mathrm{a}$ & 12 \\
\hline Silt, \% & $20-50$ & $35 \mathrm{a}$ & 8 & $20-50$ & $34 \mathrm{a}$ & 9 \\
\hline Sand, $\%$ & $14-63$ & $32 \mathrm{a}$ & 16 & $14-63$ & $32 \mathrm{a}$ & 16 \\
\hline CCE, \% & $36-62$ & $46 a$ & 6 & $38-57$ & $46 \mathrm{a}$ & 5 \\
\hline $\mathrm{pH}$ & $7.60-8.21$ & $7.97 \mathrm{a}$ & 0.13 & $7.58-8.34$ & $7.98 \mathrm{a}$ & 0.15 \\
\hline $\mathrm{EC}, \mathrm{dS} \mathrm{m}^{-1}$ & $0.3-4.21$ & $1.0 \mathrm{a}$ & 1.1 & $0.3-5.5$ & $1.2 \mathrm{a}$ & 1.6 \\
\hline $\mathrm{CEC}, \mathrm{cmol}+/ \mathrm{kg}$ & $7-21$ & $11 \mathrm{a}$ & 4 & $6-19$ & $10 \mathrm{a}$ & 4 \\
\hline
\end{tabular}

$S E$ standard error, $C C E$ calcium carbonate equivalent 

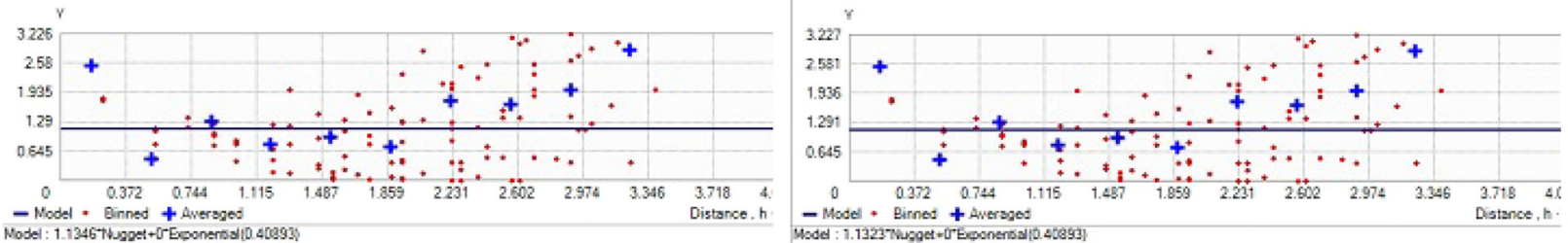

\section{Ordinary}
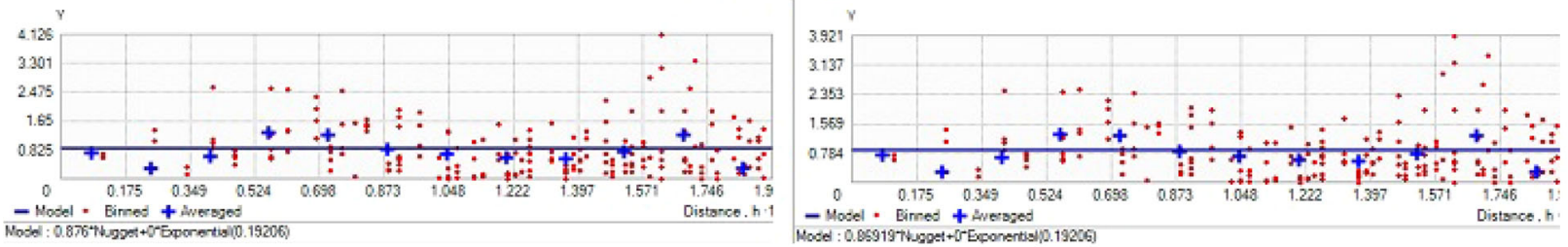

Simple
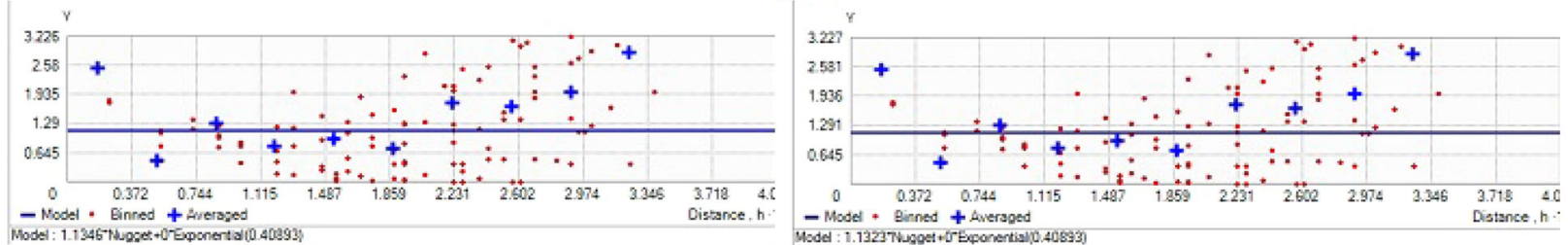

\section{Universal}
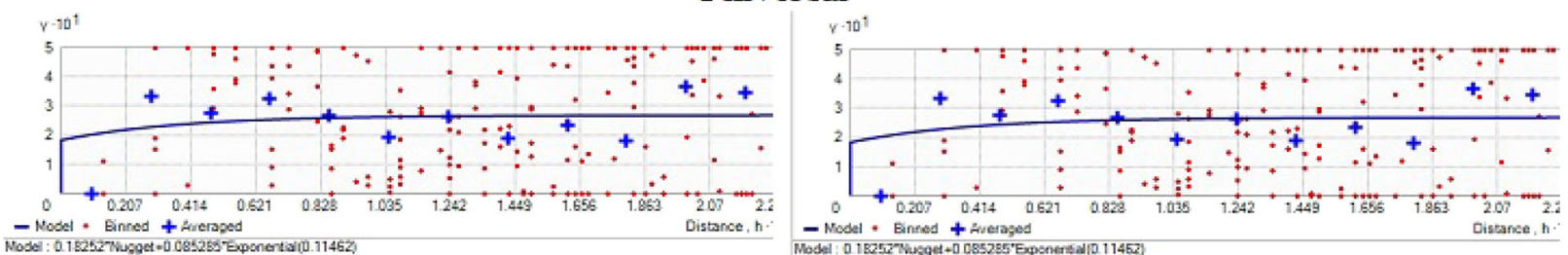

Indicator
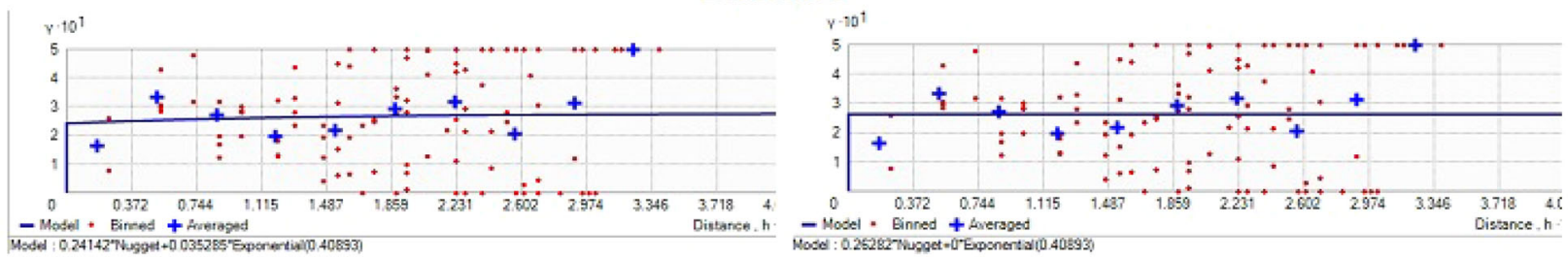

\section{Probability}

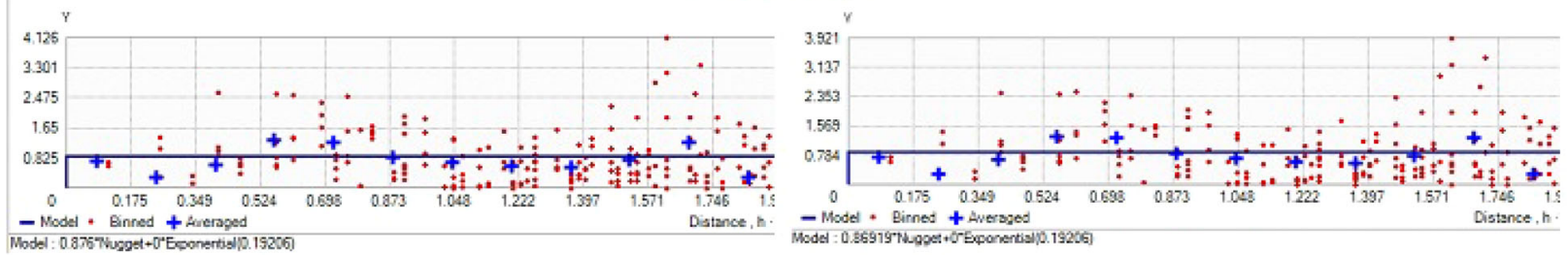

\section{Disjunctive}

Fig. 2 The semivariograms (exponential model of Kriging) for the EC data in the surface a and subsurface, $\mathbf{b}$ soils 
Table 3 The RMSE values of EC prediction by the Kriging models

\begin{tabular}{lllllll}
\hline Model & Ordinary & Simple & Universal & Indicator & Probability & Disjunctive \\
\hline RMSE & & & & & & \\
Surface soil & 1.042 & 1.011 & 1.043 & 0.518 & 0.520 & 1.017 \\
Subsurface soil & 1.041 & 1.011 & 1.042 & 0.518 & 0.509 & 1.017 \\
\hline
\end{tabular}
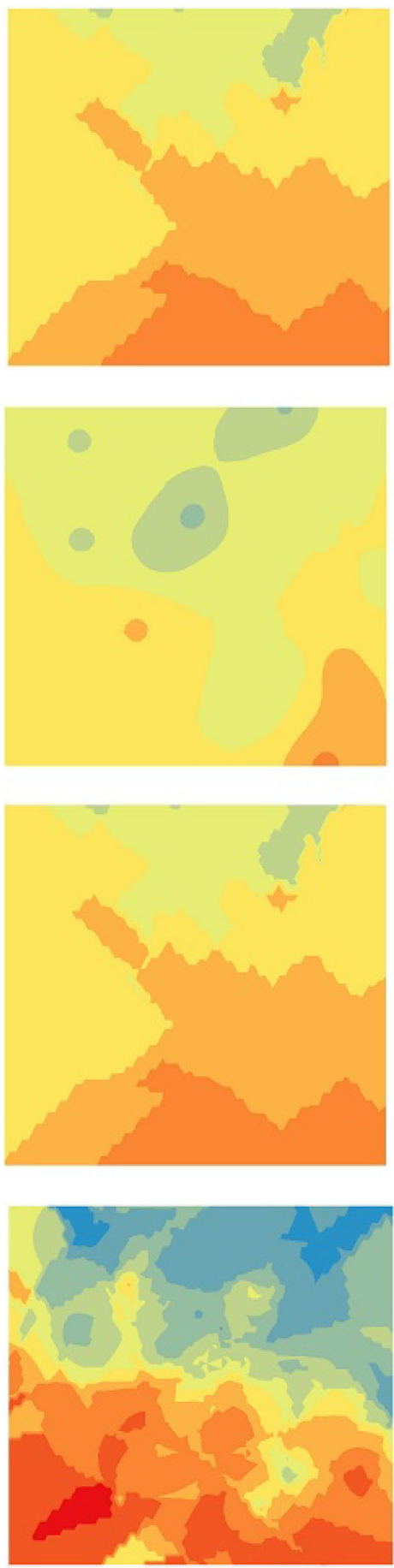

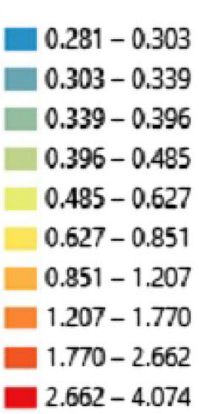

\section{Ordinary}
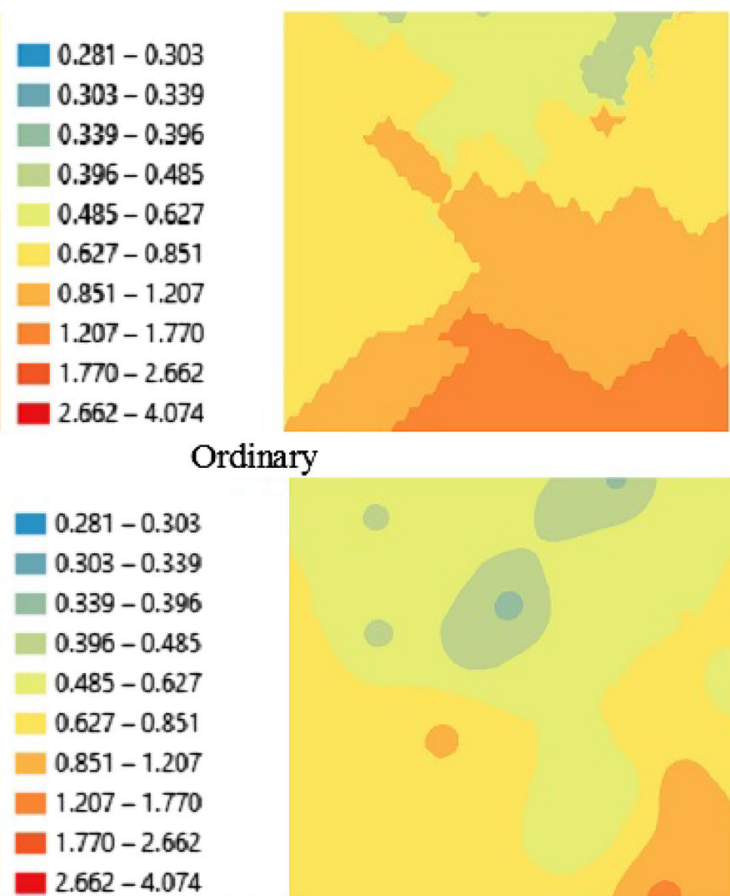

$0.28-0.302$

$0.302-0.338$

$0.338-0.394$

$0.394-0.484$

$0.484-0.625$

$0.625-0.850$

$0.850-1.205$

$1.205-1.768$

$1.768-2.659$

$2.659-4.07$

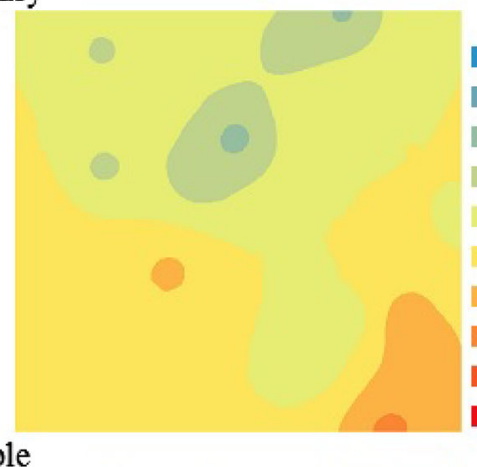

$0.28-0.302$

$0.302-0.338$

$0.338-0.394$

$0.394-0.484$

$0.484-0.625$

$0.625-0.850$

$0.850-1.205$

$1.205-1.768$

$1.768-2.659$

$2.659-4.07$

\section{Simple}

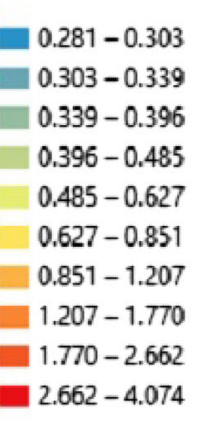

$0.28-0.302$

$0.302-0.338$

$0.338-0.394$

$0.394-0.484$

$0.484-0.625$

$0.625-0.850$

$0.850-1.205$

$1.205-1.768$

$1.768-2.659$

$2.659-4.07$

\section{Universal}
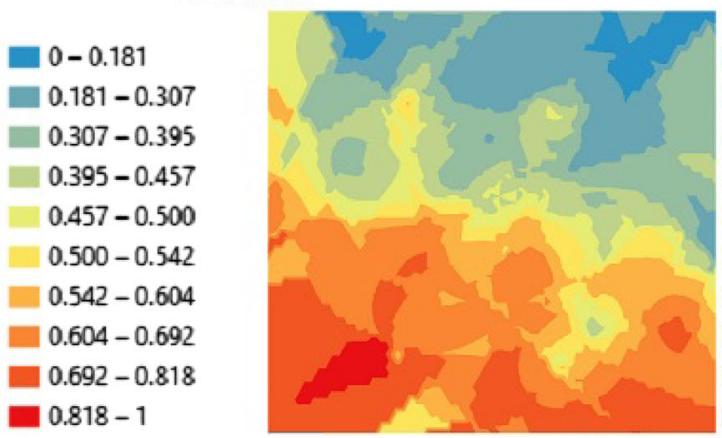

$0-0.181$

$0.181-0.307$

$0.307-0.395$

$0.395-0.457$

$0.457-0.500$

$0.500-0.542$

$0.542-0.604$

$0.604-0.692$

$0.692-0.818$

\section{Indicator}

Fig. 3 Interpolation map of models for surface and subsurface soils 

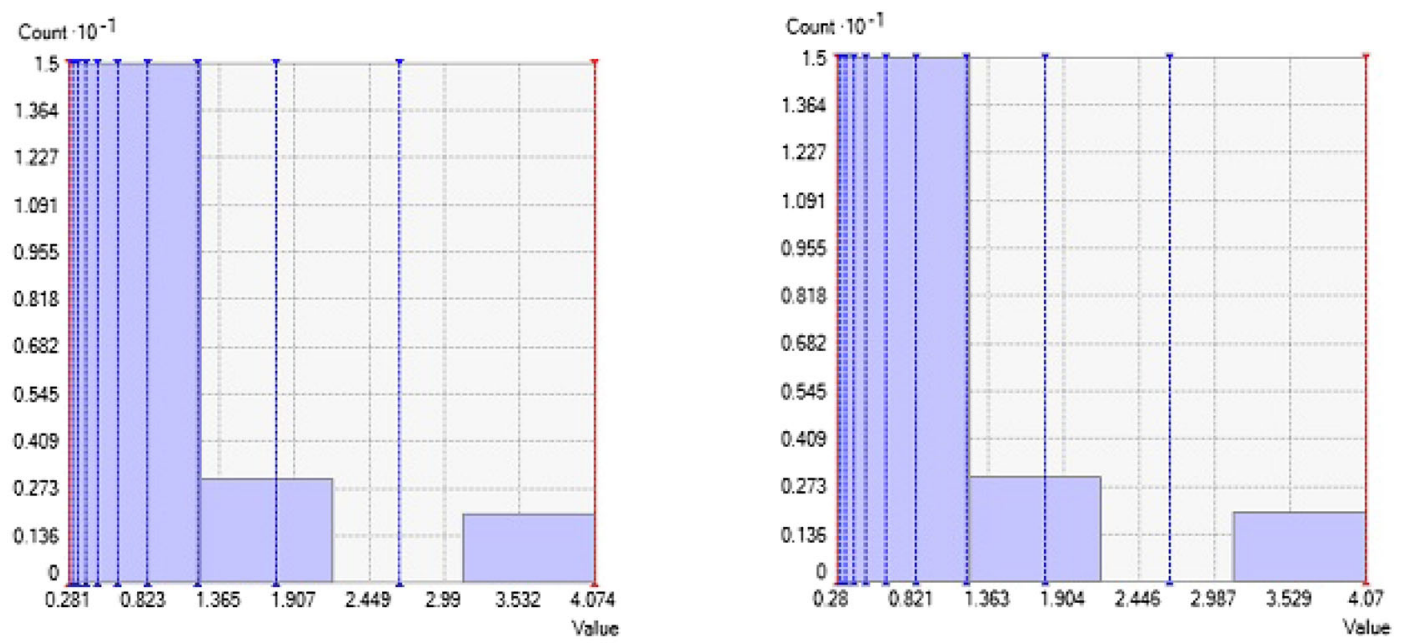

\section{Ordinary}
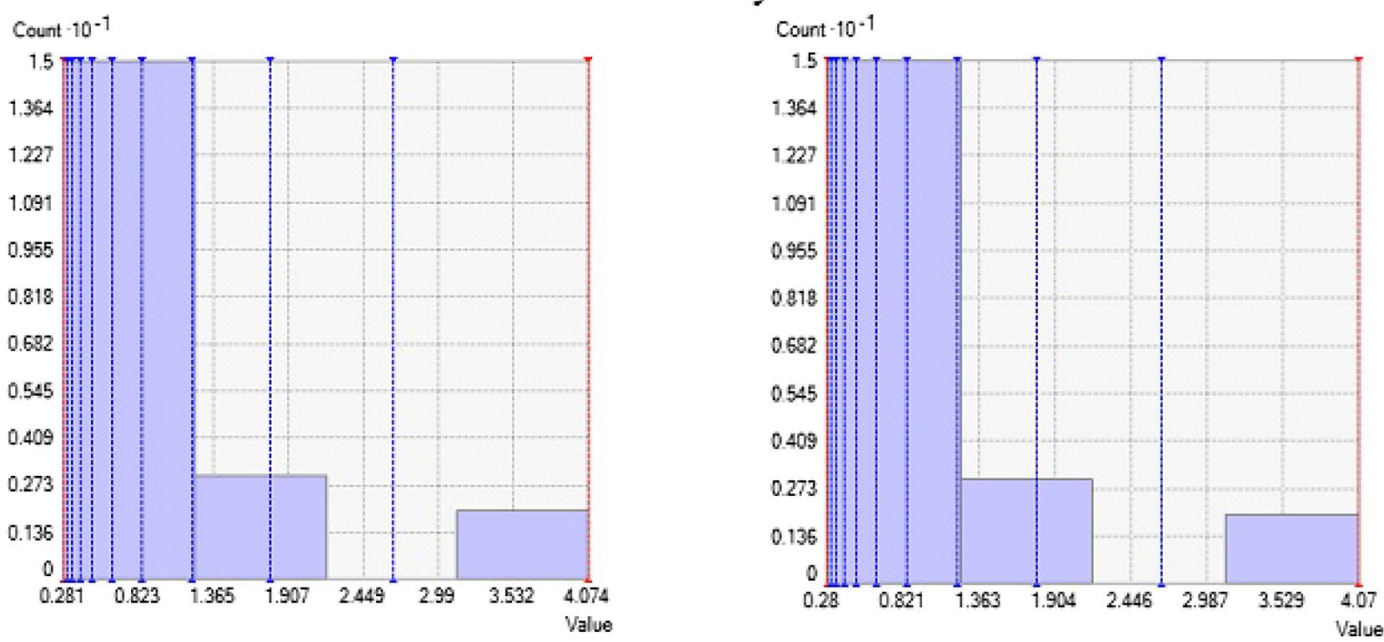

Simple
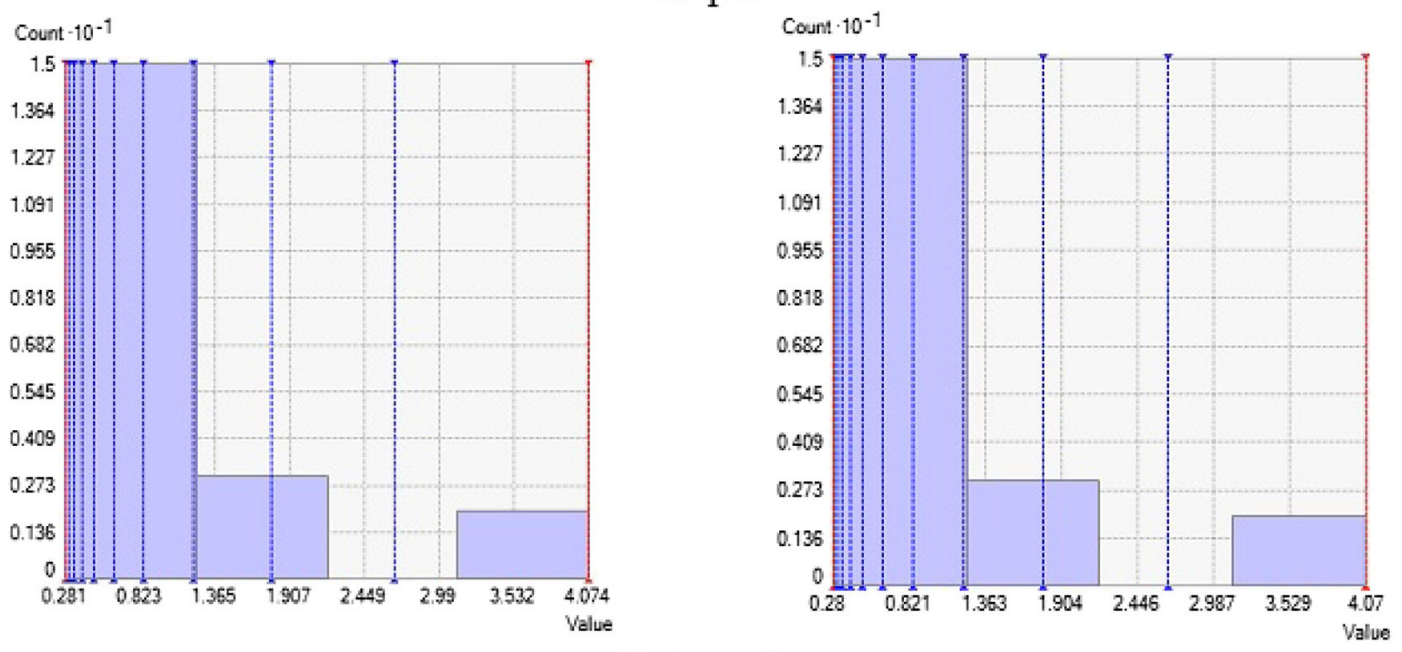

\section{Universal}

Fig. 4 Histogram of all models predicting EC values 

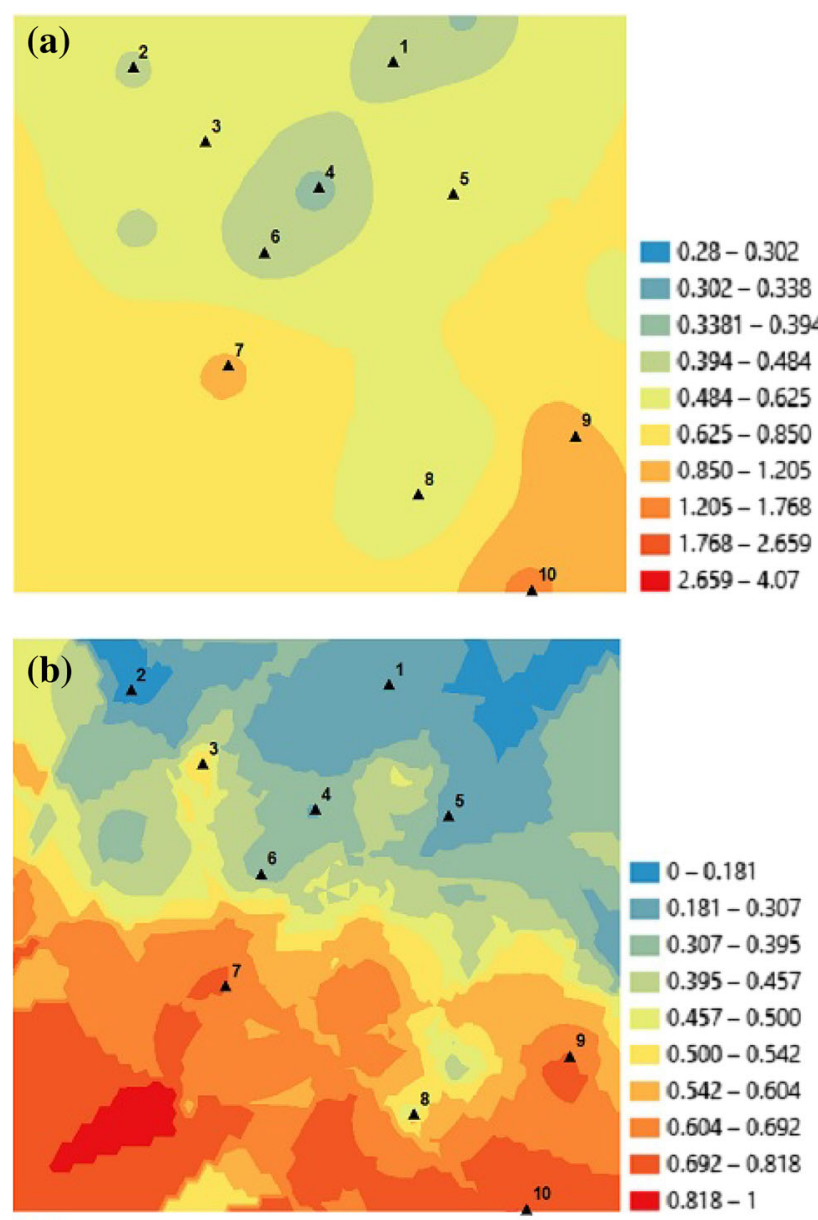

Fig. 5 Location of 10 sample points: a surface soils, b subsurface soils

\section{Geostatistical analysis}

Geostatistical analysis of data consisted of two phases. First, the semivariogram wizard was used to fit a model to EC data for the studied area. This model was then used to create the EC distribution map.
The semivariograms of the EC data of surface and subsurface soils for Ordinary, simple, universal, indicator, probability and disjunctive models are shown in Fig. 2.

RMSE was used to select the best model describing EC distribution. The RMSE values for each model were calculated (Table 3). As shown in Table 1, the best models for prediction of the EC in the studied area were indicator and probability for surface and subsurface soils, respectively.

According to Fig. 2, the best line for the prediction of EC is blue line (Model). Also the semivariogram of the EC data for exponential model was indicator with nugget, sill and lag size equal to $0,0.277$ and 0.0189 , respectively. On the other hand, the best model for subsurface soils was probability with nugget, sill and lag size equal to $0.263,0$ and 0.0340 , respectively.

In fact, semivariograms are formed by three constituents: sill, range and nugget. Semivariance is increased to a maximal asymptotic value (sill) with increasing lag between samples. With this lag, semivariance is approached the observation variance. This lag is called range beyond which variables are independent with no correlations. When semivariogram is not started exactly at intersection of coordinates generally occurs nugget that due to laboratory test errors, a sharp variation of soil properties or when sampling distance is greater than range. (Mashayekhi et al. 2007).

The spatial patterns of EC data estimated by kriging method (exponential model) for surface and subsurface soils were shown in Fig. 3.

According to Fig. 3, the spatial patterns of EC show that the EC value in the south of the studied area is higher than the others. As shown in Fig. 3, the EC values for surface and subsurface soils were classified to 10 classes. The value of the each class is shown in Fig. 4. The results of the histograms show that only indicator and to somewhat probability models have the normal distribution for EC values in surface and subsurface soils.

According to Fig. 4, indicator and universal models were found respectively as the suitable and
Table 4 The measured and estimated values of the EC for surface and subsurface soils

\begin{tabular}{llllll}
\hline Sample points & \multicolumn{2}{l}{ Surface soils } & & \multicolumn{2}{l}{ Subsurface soils } \\
& Measured values & Estimated values & & Measured values & Estimated values \\
\hline 1 & 0.34 & 0.216 & 0.34 & 0.41 \\
3 & 0.34 & 0.168 & 0.34 & 0.45 \\
4 & 0.71 & 0.537 & 0.71 & 0.56 \\
5 & 0.28 & 0.30 & 0.28 & 0.36 \\
6 & 0.41 & 0.29 & 0.41 & 0.52 \\
7 & 0.31 & 0.33 & 0.32 & 0.40 \\
8 & 1.89 & 0.73 & 1.89 & 0.91 \\
9 & 0.31 & 0.46 & 0.32 & 0.45 \\
10 & 0.61 & 0.68 & 0.61 & 0.89 \\
RMSE & 1.72 & 0.82 & 1.72 & 1.40 \\
\hline
\end{tabular}




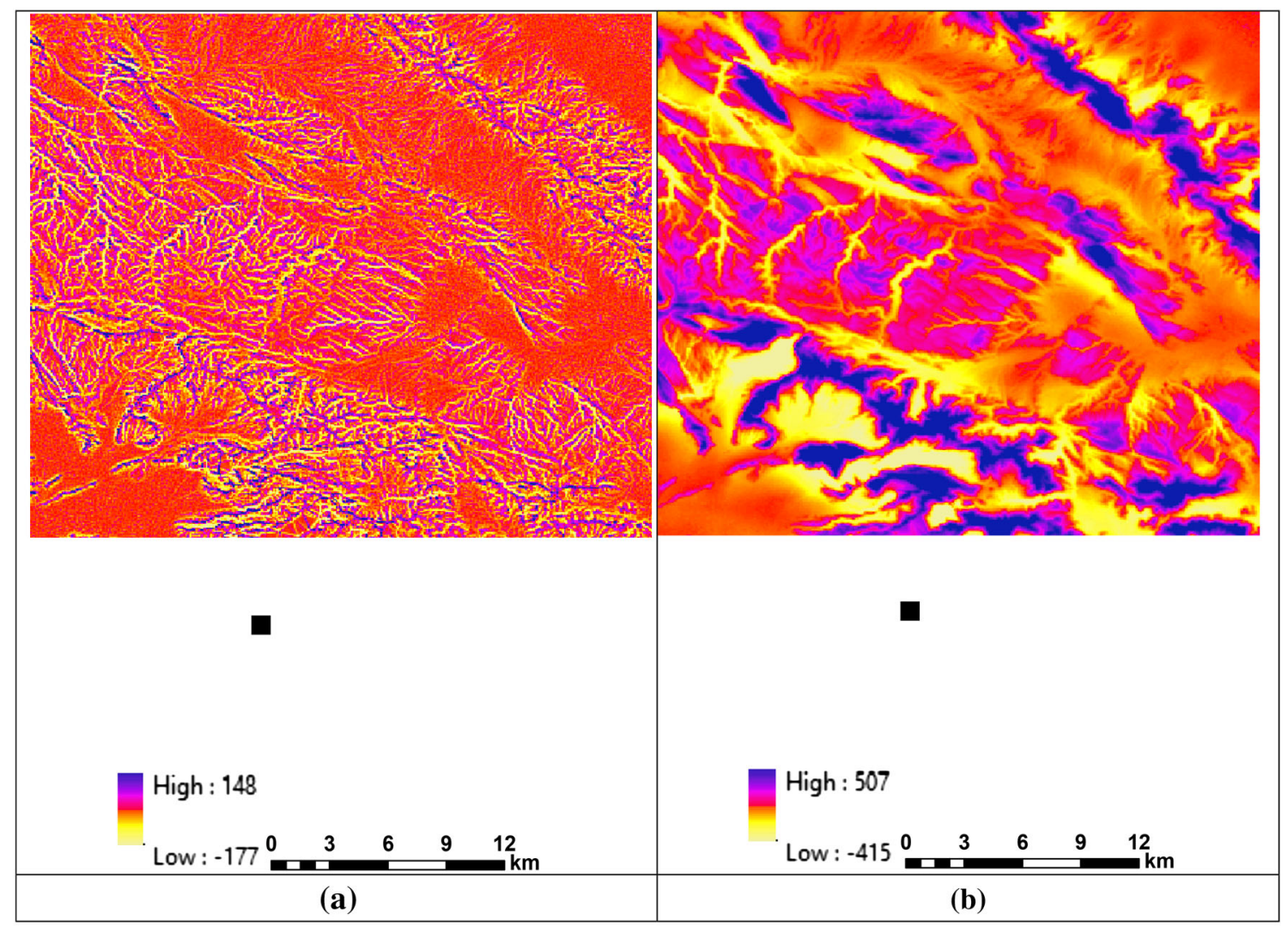

Fig. 6 TPI maps generated using a small (3 cell) and b large (45 cell) neighborhood

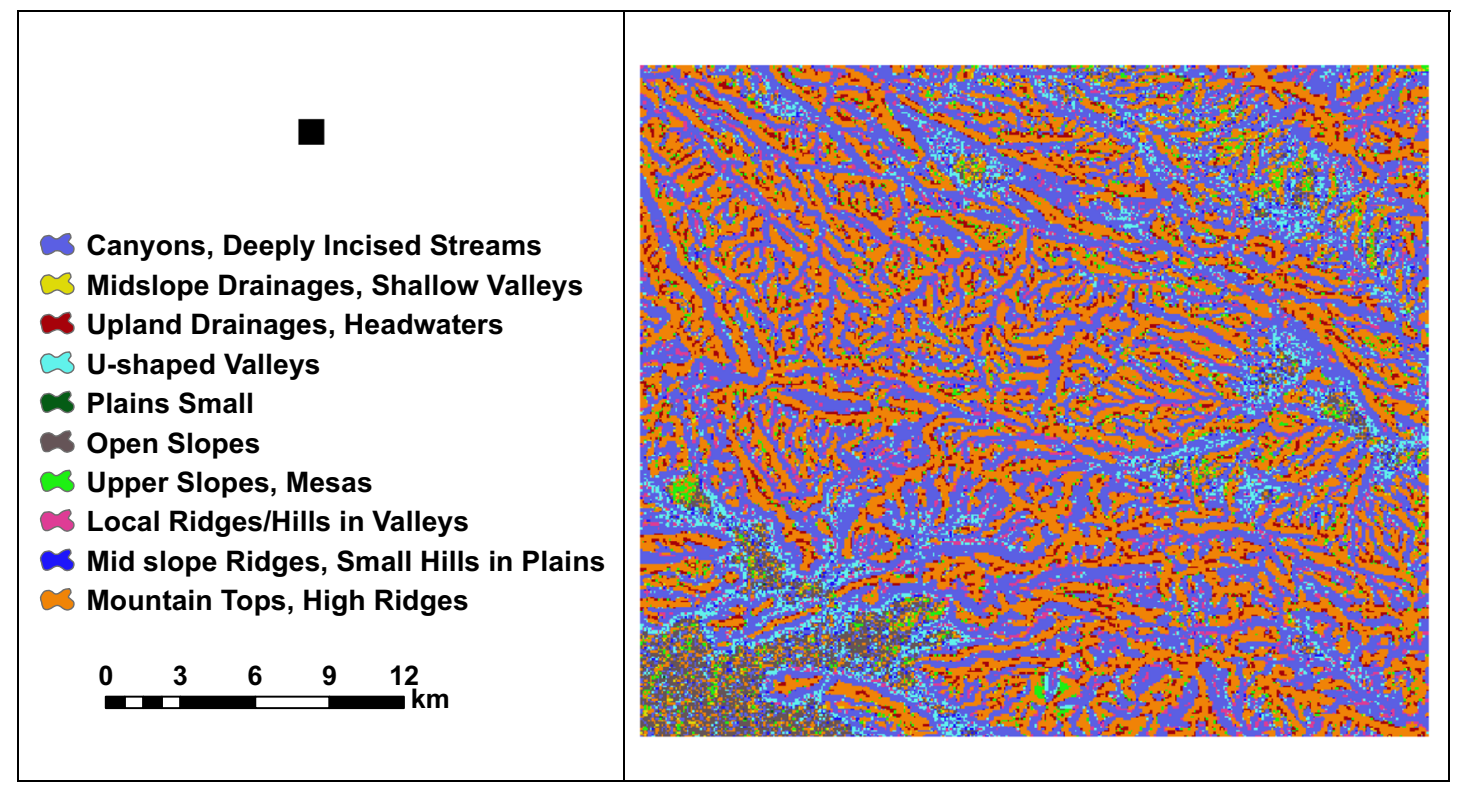

Fig. 7 Landform classification using the TPI method

unsuitable methods to estimate EC in the surface soils. On the other hand, suitable and unsuitable models for subsurface soils were probability and universal models.
For determination of accuracy of the indicator kriging (in the surface soils) and probability (in the subsurface soils) 10 sample points were used. Location of sample 
Fig. 8 Area values of each the landform classes

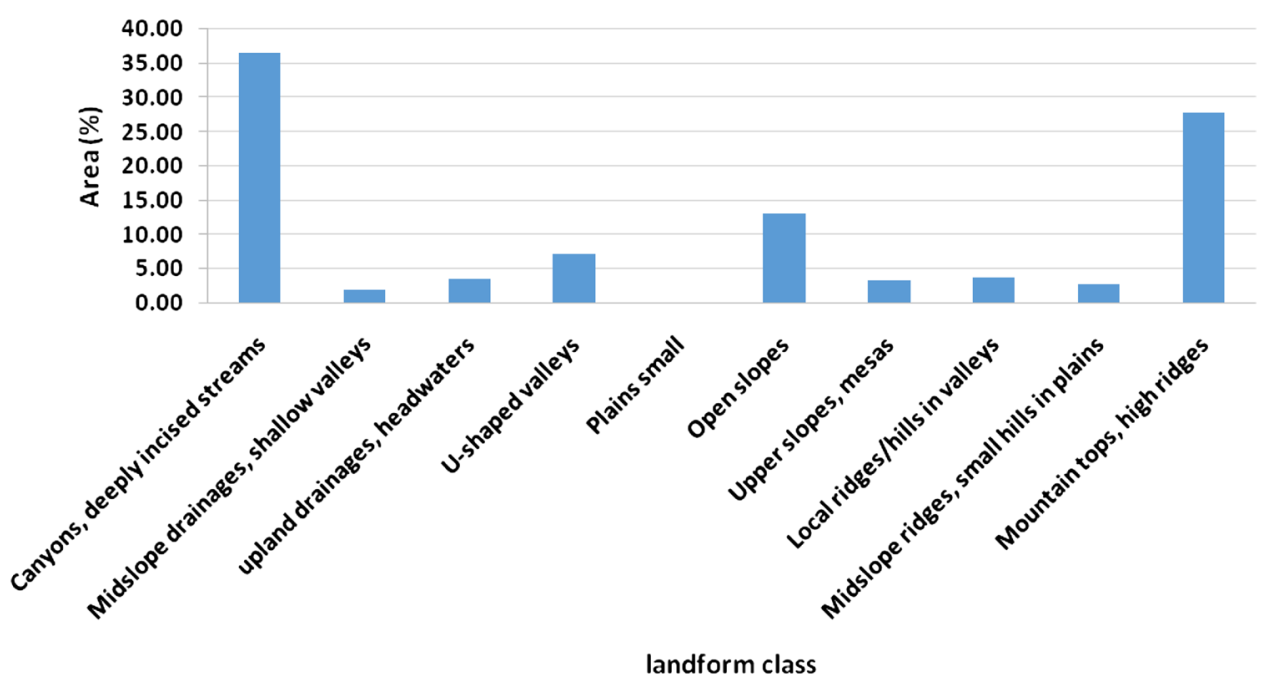

Fig. 9 Relationship between landform classes and EC value in the study area

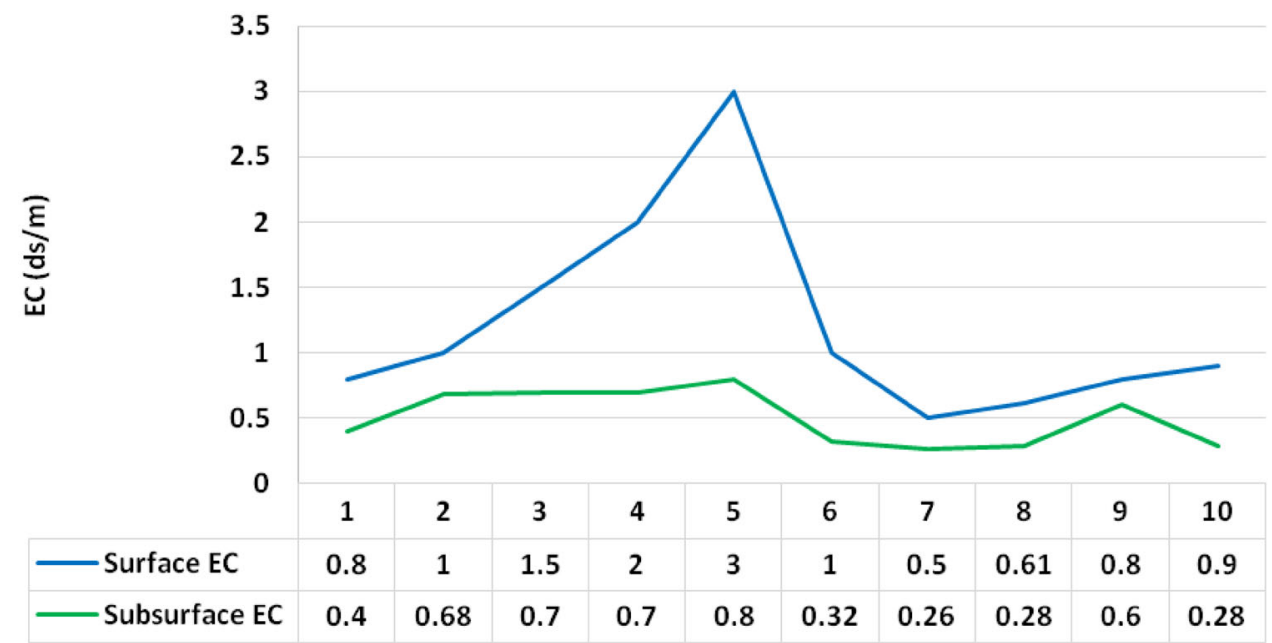

points are shown in Fig. 5. The results showed that RMSE of measured values for surface and subsurface soils were 0.476 and 0.349 , respectively.

Results showed that the RMSE value for EC in the surface and subsurface soils were 0.476 and 0.349 , respectively (Table 4) that may be due to the irregular distribution.

Finally for determination of relationship between landform classes and EC values used topographic position index (TPI) (Weiss 2001). The TPI maps generated using small and large neighborhoods are shown in Fig. 6. TPI is between -177 and 148 and -415 and 507 for 3 and 45 cells respectively (Fig. 6). The landform maps generated based on the TPI values are shown in Figs. 7, 8.

To determination of relationship between landform classes and EC value used 20 sample points. The results of landform classes and EC value were shown in Fig. 9.

According to Fig. 9, the high EC value was shown in plain small for subsurface soil $(>0.8 \mathrm{ds} / \mathrm{m})$ and surface soil
$(>3 \mathrm{ds} / \mathrm{m})$ in the study area. While the low EC value was seen in mountain top and stream for subsurface soil $(<0.8 \mathrm{ds} / \mathrm{m})$ and surface soil $(<0.4 \mathrm{ds} / \mathrm{m})$ that was indicative leaching of the soil.

\section{Conclusions}

Soil salinity is a factor that affect plant growth and development especially in arid region. The results of stepwise multiple regressions indicate that in the surface and subsurface soils, sand and silt contents respectively are the most influential soil characteristics that predict EC. The use of different models of kriging including ordinary, simple, universal, indicator, probability and disjunctive and comparison of RMSE indicated that indicator and probability were the best models for prediction of EC in the surface and subsurface soils, respectively. The spatial patterns of EC show that the EC value in the south of the 
studied area is higher than the others. RMSE value for 10 sample points of surface and subsurface soils were 0.476 and 0.349 , respectively that may be due to the irregular distribution of points. It is recommended that other interpolation methods such as co-kriging and soil properties such as CEC and SAR are used in order to prepare precision maps in the future. Also the results of relationship between EC and landform classes show that the high EC value was shown in plain small for subsurface soil and surface soil in the study area. While the low EC value was seen in mountain top and stream for subsurface soil and surface soil that was indicative leaching of the soil.

\section{References}

Akpabio GT, Agbasi OE (2011) Comparative Study of Electrical Conductivity and Salinity of Three Land Form in Akwa Ibom State. Int J Pure Appl Phy. ISSN 0973-1776. 7(2):145-150

Chapman HD (1965) Cation exchange capacity. In: Black CA (ed) Methods of soil analysis, part 2. American Society of Agronomy, Madison, pp 891-901

Corwin DL, Lesch SM (2003) Application of soil electrical conductivity to precision agriculture: theory, principles, and guidelines. Agron J 95:455-471

Cressie C (1990) The origins of Kriging. Math Geol 22:239-252

Goovaerts P (1999) Geostatistics in soil science. Geoderma 89:1-45

Gundogdu KS, Guney I (2007) Spatial analyses of groundwater levels using universal kriging. J Earth Sys Sci 116(1):49-55

Kazemi, HP, Sarvestani ZT, Kamkar B, and Shataei S, Sadeghi S (2012) Comparison of interpolation methods for estimating $\mathrm{pH}$ and EC in agricultural fields of Golestan province (north of Iran). Int J Agric Crop Sci 4:157-167

Krige DG (1951) A statistical approach to some basic mine valuation problems on the Witwatersrand. J Chemical. Metallurgical and Mining Soc. South Africa 52:119-139

Li HY, Webster R, Shi Z (2015) Mapping soil salinity in the Yangtze delta: REML and universal kriging (E-BLUP) revisited. Geoderma 237-238(2015):71-77
Mashayekhi K, Asadi Z, Movahedi Naeini SA, Hajrasuliha S (2007) Salinity regionalization with geostatistic method in a wet soil in southern Lenjan-Isfahan (Iran). Indian J Agric Res 41:1-9

Mueller TG, Hartsock NJ, Stombaugh TS, Shearer SA, Cornelius PL, Barnhise RI (2003) Soil electrical conductivity map variability in limestone soil overlain by loess. Agron J 95:496-507

Pisinaras V, Tsihrintzis VA, Petalas C, Ouzounis K (2010) Soil salinization in the agricultural lands of Rhodope District, northeastern Greece. Environ Monit Assess 166:79-94

Robinson TP, Metternicht G (2006) Testing the performance of spatial interpolation techniques for mapping soil properties. Comput Electron Agri 50:97-108

Roshan G, Negahban S (2015) Modeling of the effects of climate change on rainy and gully erosion potential of Kor-chamriz watershed in Fars province. Model Earth Syst Environ 1:26

Rowell DL (1994) Soil Science: Methods and applications. Longman Scientific and Technical, UK

Salinity Laboratory Staff (1954) Diagnosis and Improvement of Saline and Alkali Soils. Handbook No. 60, United States Department of Agriculture, Washington, DC

Shi J, Wang H, Xu J, Wu J, Liu X, Zhu H, Yu C (2007) Spatial distribution of heavy metals in soils: a case study of Changxing China. Environ Geol 52:1-10

Sun YX, Wu CZ, Zhu K, Cui Z, Chen X, Zhang F (2009) Influence of interpolation method and sampling number on spatial prediction accuracy of soil Olsen-P. Chin J Appl Ecol 20:673-678

Sun W, Whelan BM, Minasny B, McBratney AB (2012) Evaluation of a local regression Kriging approach for mapping apparent electrical conductivity of soil (ECa) at high resolution. J Plant Nutr Soil Sci 175:212-220

Webster R (1994) The development of Pedometrics. Geoderma 62:1-15

Webster R, Oliver MA (2001) Geostatistics for environmental scientists. Wiley, New York

Weiss A (2001) Topographic Positions and Landforms Analysis (Conference Poster). ESRI International User Conference. San Diego, pp 9-13

Zhang CS, Selinus O, Schedin J (1998) Statistical analyses on heavy metal contents in till and root samples in an area of southeastern Sweden. Sci Total Environ 212:217-232

Zhang CS, Selinus O, Wong P (2000) Spatial structures of cobalt, lead, and zinc contents in tills in southeastern Sweden. GFF (Trans Geol Soc Stockholm) 122(2):213-217 